\title{
Application of laser induced fluorescence to monitor atmospheric polycyclic aromatic hydrocarbons
}

\author{
P. B. C. Forbes \& E. R. Rohwer \\ Department of Chemistry, University of Pretoria, South Africa
}

\begin{abstract}
Polycyclic aromatic hydrocarbons (PAHs) are ubiquitous environmental pollutants that are of concern due to their potential human health effects. A laser induced fluorescence (LIF) selective screening technique has been developed based on the sampling of atmospheric PAHs onto a novel silicone rubber trap. After fluorescence screening, analytes on the traps can be quantified by thermal desorption-gas chromatography-mass spectrometry (TD-GC-MS). The use of the traps in a denuder configuration, where two traps in series are separated by a quartz fibre filter, allows for the monitoring of both gaseous and particle phase PAHs, which is important from a human health impact perspective.

This paper reports on the application of the denuder technology and LIF method to the monitoring of PAH emissions produced from household fires, diesel internal combustion engines, sugar cane burning and industrial emissions in South Africa. Naphthalene was found to be the most abundant PAH in all cases, with gaseous concentrations monitored in the primary trap ranging from $1.8 \mu \mathrm{g} \cdot \mathrm{m}^{-3}$ (diesel vehicular emissions) to $26 \mu \mathrm{g} \cdot \mathrm{m}^{-3}$ (industrial emissions). Breakthrough of naphthalene occurred at sampling volumes $>5 \ell$. Total transfer and detection of analytes collected on the traps is possible with TD-GC-MS, which enhances detection limits and allows for shorter sampling times and flow rates. It has been demonstrated that our method performs well in practical applications and real PAH concentrations.
\end{abstract}

Keywords: polycyclic aromatic hydrocarbons, laser induced fluorescence, denuder, silicone rubber trap, household fires, diesel vehicle emissions, sugar cane burning, industrial emissions. 


\section{Introduction}

Polycyclic aromatic hydrocarbons (PAHs) consist of aggregates of condensed aromatic rings and they are formed during the incomplete combustion of organic materials. PAHs are therefore ubiquitous atmospheric pollutants, due to their abundant sources including vehicular emissions, incineration and biomass burning. In addition, PAHs may persist in the environment and undergo long range atmospheric transport. Carcinogenicity is one of the potential human health impacts of PAHs, thus monitoring of these compounds is of importance.

Current analytical methods for atmospheric PAH determinations are time consuming and usually require solvent extraction of samples. This may limit the widespread monitoring of PAHs for spatial and temporal trend determinations. We therefore developed a technique which allows for the rapid screening of samples for the presence of selected $\mathrm{PAH}(\mathrm{s})$ using laser induced fluorescence (LIF), prior to direct comprehensive, quantitative analysis of samples which screen positive $[1,2]$.

The spectroscopic features of PAHs include large absorption cross-sections and high fluorescence quantum yields [3], thus fluorescence has been utilised as a means of detecting these compounds for many years in high performance liquid chromatography (HPLC), for example. Nitrogen lasers (providing $337 \mathrm{~nm}$ excitation) have been used in fibre optic based systems to determine PAHs in cigarette smoke [3], aerosols [4] and in water [5], although selectivity is limited in these systems due to the single available excitation wavelength, therefore a tuneable dye laser system has also been used [6].

In our method, air is sampled by means of a portable, battery-operated sampling pump onto re-useable multi-channel silicone rubber traps, as described by Ortner and Rohwer [7], which are both pre-concentrators and collectors of the analytes, as the polydimethylsiloxane (PDMS) serves as a solvent for the analyte species. A tuneable dye laser is then used to selectively excite the PAH(s) of interest on the trap, and the resulting fluorescence is determined at the characteristic wavelength of the target PAH(s). The LIF analysis is basically non-destructive, therefore analytes can be subsequently quantified by TD-GCMS.

The partitioning of PAHs between the gas and particle phase is of importance from a human health impacts perspective as reported by Gundel et al. [8], therefore effective sampling of the two phases may be required. This can be achieved by denudation, where the high diffusion coefficients of gas phase analytes result in their retention on a sorptive surface perpendicular to the gas flow (on the walls of the denuder), whilst particles pass through the denuder and are collected on a downstream filter. The multi-channel silicone rubber trap may be used in a denuder configuration, where two traps are placed in series (the primary and secondary trap, respectively), separated by a glass fibre filter, fig. 1 . The secondary trap collects any analyte which desorbs from the filter and any gaseous analytes which were not removed by the primary trap (denuder) under breakthrough sampling conditions. 


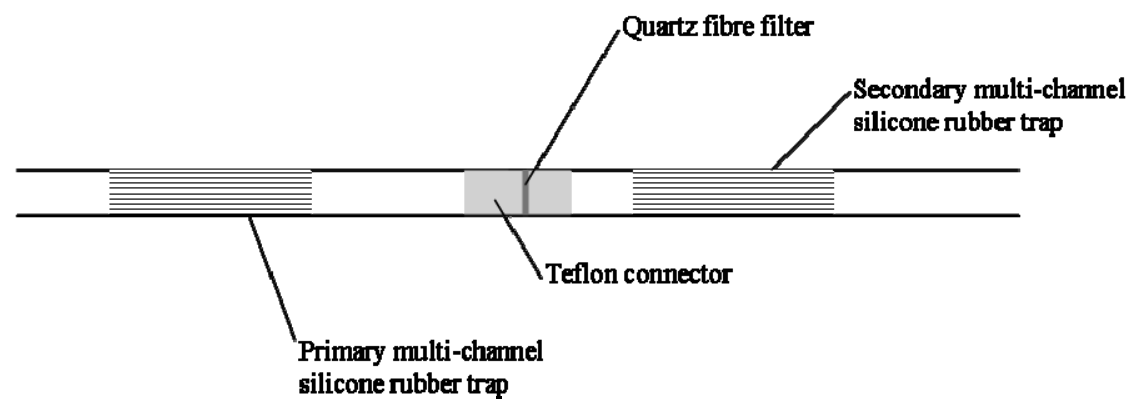

Figure 1: Multi-channel silicone rubber traps and a quartz fibre filter employed in the denuder configuration.

Our LIF and denuder methods have been tested in a number of applications, including the monitoring of emissions from industries, household fires, diesel vehicles and sugar cane burning, and the results of these South African sampling campaigns are presented in this paper. The LIF screening studies focused on naphthalene, due to the relatively high emissions of this PAH from many sources, which consequently make it an important contributor to human health effects [9]. Wauters et al. [10] also suggested naphthalene as an indicator for PAH contamination.

\section{Method}

\subsection{Household fires}

Air samples were collected adjacent to an informal trader in Pretoria, South Africa, whilst chicken was cooked over a coal and wood-fired brazier outdoors, adjacent to a busy roadway.

The multi-channel silicone rubber traps and a quartz fibre filter were employed in the denuder configuration with Teflon connections. Sampling was conducted using a portable Gilair sampling pump operating at $517 \mathrm{~m} \ell \cdot \mathrm{min}^{-1}$ for 5 min at $\sim 1 \mathrm{~m}$ above ground level and $\sim 5 \mathrm{~m}$ from the brazier. After sampling, the filter was transferred to a sealed $2 \mathrm{~m} \ell$ amber vial and the traps were end-capped and wrapped in aluminium foil.

Samples were then refrigerated prior to analysis by TD-GC-MS using a similar method to that described in Forbes and Rohwer [1]. Calibrations were performed by the analysis of $1 \mu \ell$ injections of mixed PAH standard in toluene $(1,2,10,20$ and $300 \mathrm{ng}$ for naphthalene and 1, 2, 10, 20 and $40 \mathrm{ng}$ for phenanthrene, anthracene, fluorene and pyrene) onto blank traps or clean filters.

\subsection{Diesel vehicle emissions}

The exhaust of an idling diesel vehicle (2006 Citroen C3, 1.4) was similarly sampled under cold start conditions for 11 min using portable Gilair sampling 
pumps and multi-channel silicone rubber traps in the following three configurations and flow rates:

i) Trap-filter-trap $\left(433 \mathrm{~m} \ell \cdot \mathrm{min}^{-1}\right)$

ii) Tube-filter-trap $\left(443 \mathrm{~m} \ell \cdot \mathrm{min}^{-1}\right)$

iii) Trap-trap $\left(366 \mathrm{~m} \ell \cdot \mathrm{min}^{-1}\right)$.

The samples were then analysed in the same manner as the household fire samples.

\subsection{Sugar cane burning}

Air emissions were sampled from a sugar cane burn which was conducted prior to harvest at Umhlali on the KwaZulu-Natal North Coast. The multi-channel silicone rubber traps were employed in the denuder configuration, and sampling was conducted for $10 \mathrm{~min}$ at $500 \mathrm{~m} \ell \cdot \mathrm{min}^{-1}$. A second sample was taken in the same manner after the first sample.

One set of samples (filter, primary and secondary trap) was analysed by TDGC-MS using an unoptimised method not reported here. The other set was analysed by LIF utilising a $292 \mathrm{~nm}$ excitation wavelength provided by an excimer pumped dye laser equipped with a frequency doubling crystal, as described in Forbes and Rohwer [1]. The laser beam had a diameter of $\sim 5 \mathrm{~mm}$ on the trap and had a pulse energy of $\sim 500 \mu \mathrm{J}$ in a $30 \mathrm{~ns}$ pulse. The resulting fluorescence was resolved with a scanning double monochromator equipped with a photomultiplier tube, and the results were recorded on a PC linked to an oscilloscope. After LIF analysis, the samples were refrigerated for over two years after which they were analysed by TD-GC-MS, where a mixed PAH standard was used for external calibration purposes $(0.1,1$ and $10 \mathrm{ng})$.

\subsection{Industrial emissions}

Two multi-channel silicone rubber traps in series (without a filter) were used to sample ambient air in an industrial area (Vaal region) containing an oil refinery. Samples were taken at two sites downwind (Sites 1 and 3) and at one site upwind (Site 2) of the local industries.

In order to evaluate breakthrough volumes and optimal sampling flow rates, three different sampling flow rates $\left(184,370\right.$ and $\left.1276 \mathrm{~m} \ell \cdot \mathrm{min}^{-1}\right)$, as well as different sampling intervals (10 and $25 \mathrm{~min}$ ) were employed, such that sample volumes ranged from 3.7 to $31.9 \ell$.

Samples were analysed by LIF, and a positive or negative screening result was determined upon comparison of the fluorescence emission at $323 \mathrm{~nm}$ of each trap obtained before and after sampling. The same traps were then analysed by TD-GC-MS, and six target PAHs (naphthalene, phenanthrene, pyrene, fluoranthene, fluorene and anthracene) were quantified using a mixed PAH standard for external calibration purposes $(0.1,1,10$ and $100 \mathrm{ng})$. 


\section{Results and discussion}

\subsection{Household fires}

The primary trap obtained from the open fire experiment contained $\sim 16 \mathrm{ng}$ of naphthalene $\left(6.5 \mu \mathrm{g} \cdot \mathrm{m}^{-3}\right)$, whilst negligible amounts $(<1.5 \mathrm{ng})$ were present on the filter and secondary trap, which indicates that no appreciable breakthrough of this analyte occurred with the $2.6 \ell$ sampling volume. No particle associated naphthalene was detected in the freshly formed smoke sampled.

Phenanthrene was detected on the primary trap $\left(0.6 \mu \mathrm{g} \cdot \mathrm{m}^{-3}\right)$ and $0.8 \mu \mathrm{g} \cdot \mathrm{m}^{-3}$ of pyrene was found on both the primary and secondary trap. The portion of pyrene present in the secondary trap would have arisen from blow off of particleassociated pyrene from the filter. Our results thus show that in the fresh, particle laden smoke plume, phenanthrene (3 aromatic rings) was present only in the gas phase, whilst the pyrene (4 aromatic rings) was distributed approximately equally between the gas and particle phases.

This experiment was useful in testing the naphthalene breakthrough volume under practical conditions. The denuder system performed well in that gas phase naphthalene was successfully retained in the primary trap, thus no breakthrough occurred for this $\mathrm{PAH}$, which is not particle associated at room temperature. Should any other PAHs be found in the secondary trap in other experiments performed under similar conditions, it can be inferred that they originated from blow off of PAHs from the particle phase collected on the filter, due to the fact that naphthalene is the PAH with by far the lowest breakthrough volume.

The results also confirmed the importance of naphthalene as an indicator for PAHs derived from this type of source, as naphthalene was present at the highest levels. This is in agreement with the results of a study on domestic indoor air quality in Burundi by Viau et al. [11], where an average naphthalene concentration of $29 \mu \mathrm{g} . \mathrm{m}^{-3}$ was found. It should be noted that indoor fuel burning is also common in South Africa, where $26.3 \%$ of over 13 million households rely on paraffin or wood for cooking purposes [12]. The large disease burden associated with indoor air pollution from solid fuel use has resulted in this source being a major concern in global health [13].

\subsection{Diesel vehicle emissions}

The results of the diesel vehicle emission monitoring experiments are summarized in Table 1. The primary trap of the trap-filter-trap sampling configuration contained significantly more naphthalene than any of the other traps, due to the positioning of this sampling system, which placed the trap closer to the emission source than the other two sampling configurations. This impacted on the results due to the gusty wind conditions experienced during sampling. The same amount of naphthalene was collected in the primary trap of the trap-trap configuration and in the trap of the tube-filter-trap configuration, which confirmed that no gas phase naphthalene was adsorbed onto the filters during sampling. Although the filter was blackened due to particle loading, no 
particle-associated naphthalene was found thereon at the sampling temperature $\left(28{ }^{\circ} \mathrm{C}\right)$, as was expected due to its volatility. Visual inspection of the filters and traps showed that particles had been successfully collected on the filters and had not been lost in the primary trap. No breakthrough of naphthalene was evident from the content of the secondary traps at the low sample volumes employed (4.0 to $4.9 \ell$ ), and no fluorene, anthracene, phenanthrene or pyrene were detected in any of the samples. As a result of the low sample volumes and the TD-GCMS analytical method employed, the sampling system could not be effectively tested as a denuder for the low concentration, heavier PAHs in this experiment.

Table 1: Naphthalene concentrations $\left(\mu \mathrm{g} \cdot \mathrm{m}^{-3}\right)$ in diesel vehicle emissions sampled onto multi-channel silicone rubber traps and quartz fibre filters with TD-GC-MS analysis. na $=$ not applicable; $n d=$ not detected $(<1 \mathrm{ng})$.

\begin{tabular}{|c|c|c|c|}
\hline $\begin{array}{c}\text { Sampling } \\
\text { configuration }\end{array}$ & Primary trap & Filter & Secondary trap \\
\hline Trap-filter-trap & 4.3 & nd & nd \\
\hline Tube-filter-trap & na & nd & 1.8 \\
\hline Trap-trap & 1.8 & na & nd \\
\hline
\end{tabular}

The importance of emissions from road traffic as a source of PAHs has been noted in numerous studies [14], since the isolation and identification of various carcinogenic compounds in gasoline engine exhaust gas [15]. In addition to road traffic, it should be noted that diesel combustion engines are also used to power equipment in underground mining operations in South Africa, which is therefore another potential source of PAH exposure.

\subsection{Sugar cane burning}

Visual inspection of the traps after sampling clearly showed that the fine particles had passed through the first silicone trap, and were present on the filter. LIF results of the traps focused on naphthalene (292 nm excitation), which showed a concentration profile through the sampling system (fig. 2), and was present on the primary and secondary trap, with possible overlap of heavier PAH emission spectra at the inlet side of the first trap. The samples therefore screened positive for naphthalene via the LIF method, indicating the need for quantitative GC-MS analysis, proving the concept of our LIF method as a screening tool.

The first set of TD-GC-MS results displayed significant co-elution with respect to the naphthalene peak. The PAHs were not fully quantified but peak areas were compared for the filter, primary and secondary traps, respectively. The first trap contained $\sim 1 \mathrm{ng}\left(0.2 \mu \mathrm{g} . \mathrm{m}^{-3}\right)$ of naphthalene (comparison with peak area of a $0.1 \mathrm{ng}$ naphthalene standard analysis), whilst very small amounts were present on the filter, as expected for this volatile compound. Due to their lower volatility, higher proportions of phenanthrene, fluoranthene and pyrene were present in the particle phase (2, 9 and $12 \%$ respectively). Godoi et al. [16] have 


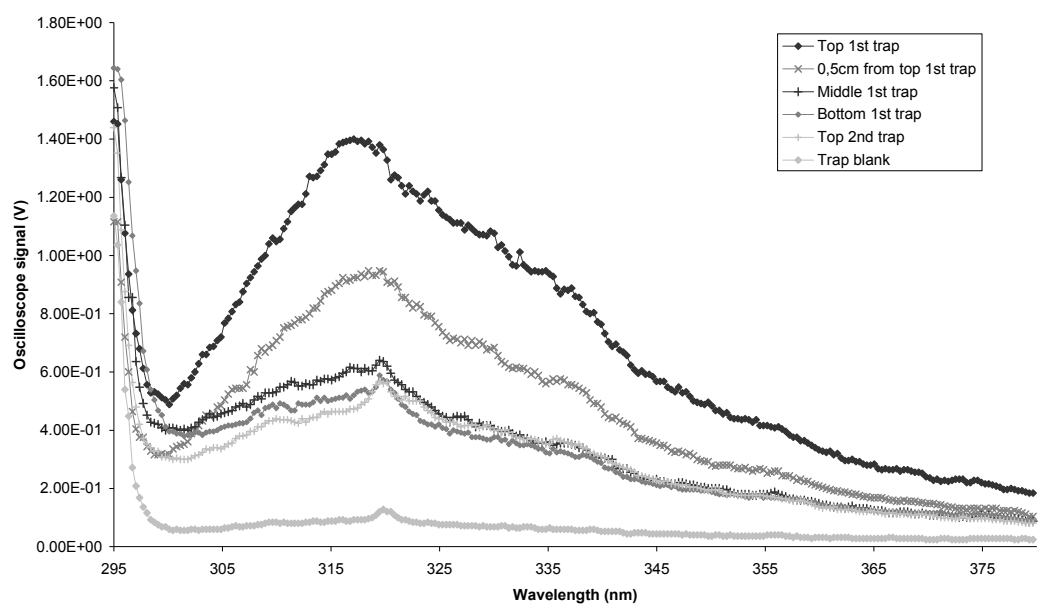

Figure 2: $\quad$ Fluorescence emission spectra of the primary $\left(1^{\text {st }}\right)$ and secondary $\left(2^{\text {nd }}\right)$ traps obtained from the sampling of air emissions from a sugar cane burn, with $292 \mathrm{~nm}$ excitation.

similarly shown that the naphthalene content of sugar cane soot was a factor of $\sim 7$ times lower than that of phenanthrene, fluoranthene and pyrene, with concentrations ranging from $0.42 \mathrm{ng} \cdot \mathrm{m}^{-3}$ for naphthalene to $3.3 \mathrm{ng} \cdot \mathrm{m}^{-3}$ for fluoranthene.

The second set of TD-GC-MS results proved the stability of trapped samples, as naphthalene (the most volatile $\mathrm{PAH}$ ) was still present on the traps after refrigerated storage for over two years. Better resolution was obtained with this TD-GC-MS method and the primary trap was found to contain $13 \mathrm{ng}$ of naphthalene $\left(2.6 \mu \mathrm{g} . \mathrm{m}^{-3}\right)$ and $3.3 \mathrm{ng}$ of phenanthrene $\left(0.7 \mu \mathrm{g} . \mathrm{m}^{-3}\right)$, whilst the secondary trap contained $1.8 \mathrm{ng}$ of naphthalene $\left(0.4 \mu \mathrm{g} . \mathrm{m}^{-3}\right)$, which indicates that some breakthrough had occurred at the $5 \ell$ sampling volume, which was also evident from the LIF results. The filter samples had been stored in $2 \mathrm{~m} \ell$ amber vials at room temperature, therefore volatilization losses were expected and indeed no target PAHs were found on the stored filter sample.

The multi-channel silicone rubber trap denuder system and the LIF screening method were therefore successfully tested in this application, where PAH partitioning between the gas and particle phase was evident.

In South Africa approximately 430000 hectares of sugar cane is currently under cultivation [17]. Due to the close vicinity of local communities to many of these plantations, the potential human health effects due to burning of the sugar cane are of concern, even more so for those harvesting the crop, who are occupationally exposed. 


\subsection{Industrial emissions}

No PAHs were detected on the blank traps prior to sampling by both LIF and TD-GC-MS. The post sampling results are summarized in Table 2. The various sampling flow rates and sample volumes allowed for the successful confirmation of laboratory derived breakthrough volumes for the analytes of interest, as it was evident that breakthrough only occurred at the highest sampling flow rate, where the corresponding sample volume was $31.9 \ell$.

The TD-GC-MS results at the first sampling site indicated a naphthalene concentration of between $\sim 10 \mu \mathrm{g} . \mathrm{m}^{-3}$ (for the $25 \mathrm{~min}$ samples), and $\sim 25 \mu \mathrm{g} . \mathrm{m}^{-3}$ (for the $10 \mathrm{~min}$ sample). This difference is likely due to variations in ambient air PAH concentrations over the sampling interval, as noted from the wafting chemical smell during sampling. No other target PAHs were detected.

The target PAH concentrations were all below the limit of detection of the GC-MS for the samples from the second site $(<0.1 \mathrm{ng}$ on trap). This was to be expected, as sampling was conducted upwind of the industrial sources.

The industrial odour evident at sampling site 1 was less evident during sampling at site 3 . This was reflected in the results, as the naphthalene concentration was $\sim 3 \mu \mathrm{g} . \mathrm{m}^{-3}$. Excellent reproducibility was found between traps in this case, indicating a more constant concentration over the sampling interval. No other target PAHs were detected.

Table 2: Industrial monitoring LIF screening and TD-GC-MS naphthalene results at three sampling sites and different sampling volumes. ND $=$ not detected.

\begin{tabular}{|c|c|c|c|c|c|c|}
\hline \multirow[t]{2}{*}{$\begin{array}{c}\text { Analytical } \\
\text { method }\end{array}$} & \multicolumn{2}{|c|}{$\begin{array}{c}4.6 \ell \text { sampled at } \\
184 \mathrm{~m} \ell \cdot \min ^{-1} \text { for } 25 \\
\min \end{array}$} & \multicolumn{2}{|c|}{$\begin{array}{c}3.7 \ell \text { sampled at } \\
370 \mathrm{~m} \ell \cdot \mathrm{min}^{-1} \text { for } 10 \\
\min \end{array}$} & \multicolumn{2}{|c|}{$\begin{array}{c}31.9 \ell \text { sampled at } \\
1276 \mathrm{~m} \ell \cdot \mathrm{min}^{-1} \text { for } 25 \\
\mathrm{~min}\end{array}$} \\
\hline & $\begin{array}{c}\text { Primary } \\
\text { trap }\end{array}$ & $\begin{array}{c}\text { Secondary } \\
\text { trap }\end{array}$ & $\begin{array}{c}\text { Primary } \\
\text { trap }\end{array}$ & $\begin{array}{c}\text { Secondary } \\
\text { trap }\end{array}$ & $\begin{array}{c}\text { Primary } \\
\text { trap }\end{array}$ & $\begin{array}{c}\text { Secondary } \\
\text { trap }\end{array}$ \\
\hline \multicolumn{7}{|c|}{ Sampling site 1} \\
\hline LIF & Positive & Positive & Positive & Negative & Positive & Positive \\
\hline $\begin{array}{c}\text { TD-GC-MS } \\
\begin{array}{c}(\mathrm{ng}) \\
\left(\mu \mathrm{g} \cdot \mathrm{m}^{-3}\right)\end{array}\end{array}$ & $\begin{array}{l}44 \\
9.6 \\
\end{array}$ & ND & $\begin{array}{l}95 \\
26 \\
\end{array}$ & ND & $\begin{array}{r}214 \\
6.7 \\
\end{array}$ & $\begin{array}{l}102 \\
3.2 \\
\end{array}$ \\
\hline \multicolumn{7}{|c|}{ Sampling site 2} \\
\hline LIF & Negative & Negative & Negative & Negative & Negative & Negative \\
\hline $\begin{array}{c}\text { TD-GC-MS } \\
\begin{array}{c}(\mathrm{ng}) \\
\left(\mu \mathrm{g} . \mathrm{m}^{-3}\right)\end{array} \\
\end{array}$ & ND & ND & ND & ND & ND & ND \\
\hline \multicolumn{7}{|c|}{ Sampling site 3} \\
\hline LIF & Positive & Positive & Negative & Positive & Positive & Positive \\
\hline $\begin{array}{c}\text { TD-GC-MS } \\
\begin{array}{c}(\mathrm{ng}) \\
\left(\mu \mathrm{g} \cdot \mathrm{m}^{-3}\right)\end{array}\end{array}$ & $\begin{array}{l}12 \\
2.6\end{array}$ & ND & $\begin{array}{c}11 \\
3.0\end{array}$ & ND & $\begin{array}{l}82 \\
2.6\end{array}$ & $\begin{array}{l}16 \\
0.5\end{array}$ \\
\hline
\end{tabular}




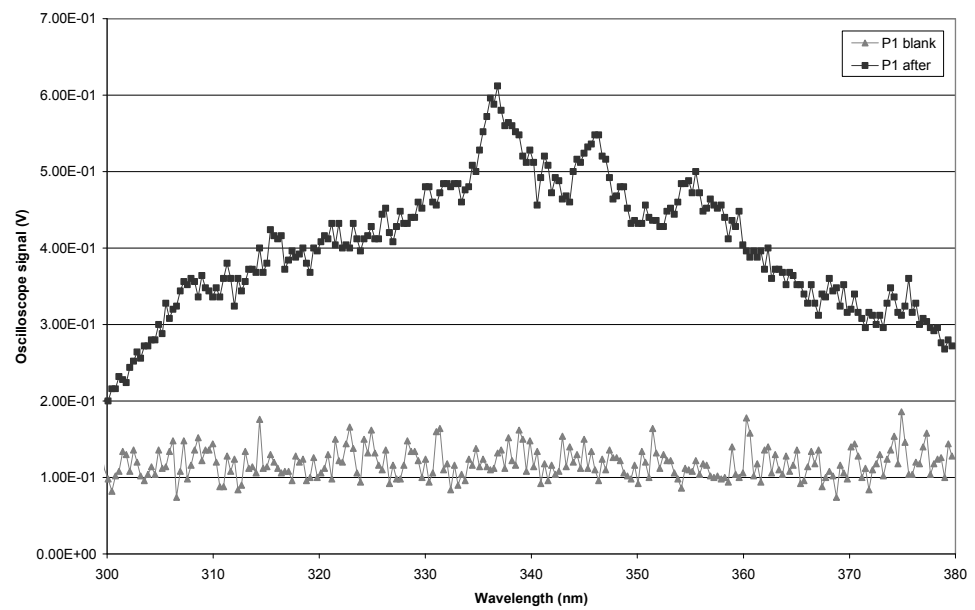

Figure 3: Laser induced fluorescence spectra of a primary trap before and after sampling at industrial site 3 , showing a positive screening result (31.9 $\ell$ of air was sampled over $25 \mathrm{~min}$, LIF excitation at 292 $\mathrm{nm})$.

An example of a fluorescence spectrum of a primary trap which screened positive is shown in fig.3. Three false positives were recorded with the LIF screening, which were all for secondary traps sampled at contaminated sites, therefore it is possible that non-target molecules of fairly high volatility, which contained fluorophores, were present in these traps. The field blank, however, also gave a false positive, although no naphthalene was detected by TD-GC-MS, as expected.

One false negative was recorded (primary trap for site 3 at $370 \mathrm{~m} \ell \cdot \mathrm{min}^{-1}$ sampling flow rate), which related to a naphthalene content of only $11 \mathrm{ng}$ over the entire trap, thus the amount of naphthalene in the top $5 \mathrm{~mm}$ spot of the trap, as analysed by LIF, was below the detection limit.

Thus overall, LIF proved to be a useful screening tool in this application, and it should be noted that false positives are more acceptable than false negatives in environmental screening applications, where a worst case scenario should be provided.

A major industrial node is found in the Highveld region of South Africa, such that the $\mathrm{NO}_{2}$ emissions from this area are clearly visible in satellite spectroscopy studies [18]. Monitoring of air pollutants in this region is therefore of importance in a global context.

\section{Conclusion}

The LIF PAH screening method and multi-channel silicone rubber trap denuder technology were tested in various applications, which demonstrated the practical 
use of the method at environmental concentrations of relevance to South Africa. The detected naphthalene concentration in the primary traps ranged from $1.8 \mu \mathrm{g} . \mathrm{m}^{-3}$ (diesel vehicular emissions) to $26 \mu \mathrm{g} \cdot \mathrm{m}^{-3}$ (industrial emissions). It was shown that long term storage of naphthalene samples is possible and that the denuder system can perform in highly particle-laden atmospheres, such as that generated during a sugar cane burn. The LIF screening method allowed for the differentiation between impacted and non-impacted industrial sampling sites, as is required of such a method.

It is clear that breakthrough of naphthalene occurred at sampling volumes $>5$ $\ell$, although larger sampling volumes than this are required for sufficient preconcentration of the lower concentration, less volatile PAHs in order to ensure that they are above the TD-GC-MS detection limit. It may therefore be necessary to sample in duplicate (one low sample volume and one higher sample volume) in order to allow for accurate quantitation by a suitable TD-GC-MS method across the range of PAH concentrations and volatilities.

Total transfer and detection of collected analyte is possible with our TD-GCMS method, which enhances detection limits and allows for shorter sampling times and flow rates. The denuder sampling system provides particle and gas phase concentrations, which is of importance for the determination of potential human health effects.

The experiments also verified the importance of naphthalene as an indicator for atmospheric PAHs, as the TD-GC-MS results showed that naphthalene was the most abundant PAH in the diverse applications which were investigated. This validates our focus on utilising the LIF method to screen for naphthalene.

\section{References}

[1] Forbes, P.B.C. \& Rohwer, E.R., Investigations into a novel method for atmospheric polycyclic aromatic hydrocarbon monitoring. Environmental Pollution, 157, pp. 2529-2535, 2009.

[2] Forbes, P.B.C., Trüe, A. \& Rohwer, E.R., Laser induced fluorescence of polycyclic aromatic hydrocarbons: An approach to gas standards. Environmental Chemistry Letters, DOI:10.1007/s10311-009-0238-6.

[3] Song, J.M., Jagannathan, R., Stokes, D.L., Vo-Dinh, T. \& Hajaligol, M.R., Real-time monitoring of polycyclic aromatic hydrocarbons in cigarette smoke using time-resolved laser-induced fluorescence. Polycyclic Aromatic Compounds, 23, pp. 429-439, 2003.

[4] Panne, U., Knöller, A., Kotzick, R. \& Niessner, R., On-line and in-situ detection of polycyclic aromatic hydrocarbons (PAH) on aerosols via thermodesorption and laser-induced fluorescence spectroscopy. Fresenius Journal of Analytical Chemistry, 366, pp. 408-414, 2000.

[5] Kotzick, R. \& Niessner, R., Application of time-resolved, laser-induced and fiber-optically guided fluorescence for monitoring of a PAH-contaminated remediation site. Fresenius Journal of Analytical Chemistry, 354, pp. 72$76,1996$. 
[6] Niessner, R., Robers, W. \& Krupp, A., Detection of particulate polycyclic aromatic hydrocarbons by laser-induced time-resolved fluorescence. Fresenius Journal of Analytical Chemistry, 341, pp. 207-213, 1991.

[7] Ortner, E.K. \& Rohwer, E.R., Trace analysis of semi-volatile organic air pollutants using thick film silicone rubber traps with capillary gas chromatography. Journal of High Resolution Chromatography, 19, pp. 339344, 1996.

[8] Gundel, L.A., Lee, V.C., Mahanama, K.R.R., Stevens, R.K. \& Daisey, J.M., Direct determination of the phase distributions of semi-volatile polycyclic aromatic hydrocarbons using annular denuders. Atmospheric Environment, 29 (14), pp. 1719-1733, 1995.

[9] Odabasi, M., Vadar, N., Sofuoglu, A., Tasdemir, Y. \& Holsen, T.M., Polycyclic aromatic hydrocarbons (PAHs) in Chicago air. The Science of the Total Environment, 227 (1), pp. 57-67, 1999.

[10] Wauters, E., Van Caeter, P., Desmet, G., David, F., Devos, C. \& Sandra, P., Improved accuracy in the determination of polycyclic aromatic hydrocarbons in air using $24 \mathrm{~h}$ sampling on a mixed bed followed by thermal desorption capillary gas chromatography-mass spectrometry. Journal of Chromatography A, 1190, pp. 286-293, 2008.

[11] Viau, C., Hakizimana, G. \& Bouchard, M., Indoor exposure to polycyclic aromatic hydrocarbons and carbon monoxide in traditional houses in Burundi. International Archives of Occupational and Environmental Health, 73, pp. 331-338, 2000.

[12] Statistics South Africa, General Household Survey (P0318), July 2008 Online. www.statssa.gov.za

[13] Ezzati, M., Indoor air pollution and health in developing countries. The Lancet, 366, pp. 104-106, 2005.

[14] Wild, S.R. \& Jones, K.C., Polynuclear aromatic hydrocarbons in the United Kingdom environment: A preliminary source inventory and budget. Environmental Pollution, 88, pp. 91-108, 1995.

[15] Hoffmann, D. \& Wynder, E.L., Studies on gasoline engine exhaust. Journal of the Air Control Association, 13 (7), pp. 322-327, 1963.

[16] Godoi, A.F.L., Ravindra, K., Godoi, R.H.M., Andrade, S.J., Santiago-Silva, M., Van Vaeck, L. \& Van Grieken, R., Fast chromatographic determination of polycyclic aromatic hydrocarbons in aerosol samples from sugar cane burning. Journal of Chromatography A, 1027, pp. 49-53, 2004.

[17] South African Sugar Association, Sugar Industry Directory for 2005/2006 Online. www.sasa.org.za

[18] British National Space Centre, www.bnsc.gov.uk/Our-Planet/Theenvironment/Pollution 